\title{
Epididymal storage at abdominal temperature reduces the time required for capacitation of hamster spermatozoa
}

\author{
J. M. Bedford $\dagger$ and R. Yanagimachi $†$ \\ $\dagger$ Departments of Obstetrics and Gynecology, and Cell Biology and Anatomy, Cornell \\ University Medical College, New York, NY 10021, USA; and $\ddagger$ Department of Anatomy \\ and Reproductive Biology, University of Hawaii School of Medicine, Honolulu, \\ Hawaii 96822, USA
}

\begin{abstract}
Summary. The epididymis was reflected unilaterally or bilaterally to the abdomen in adult hamsters, leaving normally functioning testes in the scrotum. In unilateral cases, spermatozoa taken from the abdominal cauda, 1 month or more post-operatively, underwent a reversal of head agglutination and dispersed earlier, and underwent hyperactivation and fertilized cumulus-free eggs about $30-45 \mathrm{~min}$ sooner than did spermatozoa from the contralateral scrotal cauda. In addition, spermatozoa from the abdominal cauda began to undergo a spontaneous acrosome reaction $30-45$ min earlier and to a greater extent than in control spermatozoa. Finally, in females mated at or soon after ovulation, spermatozoa ejaculated by bilaterally cryptepididymal males fertilized eggs $30-45 \mathrm{~min}$ before those from normal males. Other females mated to bilaterally cryptepididymal males gave birth to normal litters. The results are considered in terms of the possibility that temperature-sensitive sperm-binding macromolecules, which may be involved in sperm storage in the cauda epididymis, could be one determinant of the need for capacitation.
\end{abstract}

Keywords: cauda epididymidis; sperm capacitation; temperature; acrosome reaction; hamster

\section{Introduction}

The unusual requirement that mammalian spermatozoa have for capacitation before fertilization, has been recognized for 40 years (Austin, 1951; Chang, 1951). It is evident now that capacitation involves certain post-ejaculation changes in the sperm plasmalemma (for review see Bedford, 1983; Yanagimachi, 1981, 1988; Eddy, 1988; Bedford \& Hoskins, 1990), which, in appropriate conditions, may result in the appearance of a hyperactivated form of motility (Yanagimachi, 1970, 1981), and, independently, the ability to undergo the acrosome reaction (Bedford, 1970).

Observed as a phenomenon so far only in therian mammals (see Bedford, 1991a), the function of the additional step of capacitation in the mammalian fertilization process remains very much in question. It may be that hyperactivation relates to the disproportionate thickness and resilience of the eutherian zona pellucida, providing physical thrust of a quality needed to penetrate it (Katz \& Yanagimachi, 1981; Bedford, 1983). However, the idea that some element of capacitation functions as an alternative means of controlling the acrosome reaction, in the face of evolutionary change in the egg vestment (Bedford, 1983), no longer seems appropriate. Capacitated eutherian spermatozoa may indeed react spontaneously in vitro or in vivo in the absence of any product of ovulation. None the less, there is now ample evidence that the acrosome reaction can be stimulated in capacitated spermatozoa by the zona pellucida (Saling \& Storey, 1979; Bleil \& Wassarman, 1983; Cherr et al., 1986; Florman \& First, 1988; Uto et al., 1988; Cross et al., 1988) as well as cumulus oophorus (Bavister, 1982; Tesarik, 1985; Chen \& Sathananthan, 1986). 
In considering the underlying significance of the need for capacitation before an acrosome reaction can occur in mammalian spermatozoa, there seems reason now to focus attention on the system of sperm storage in the cauda epididymis. While the key factors responsible for maintenance of sperm integrity have not been identified, the evidence suggests that spermatozoa are subject to late surface modifications in the epididymis beyond those required for fertilizing ability per se.

Examples of this can be found in several species. In the rat, a glycoprotein (HIS) secreted by the cauda binds to the acrosomal surface as spermatozoa reach the large tubules of the cauda (Rifkin \& Olson, 1985). However, a proportion of spermatozoa in the lower corpus region of the rat epididymis can fertilize (Dyson \& Orgebin-Crist, 1973), although presumably devoid of this protein. Comparably, perhaps, many spermatozoa develop the ability to fertilize while in the mid- and lower corpus epididymis of the ram (Fournier-Delpech et al., 1979), and therefore well before their association with a glycoprotein of $M_{\mathrm{r}} 24000$ that is secreted by the cauda and binds to the sperm surface there (Dacheux \& Voglmayr, 1983). Again, rabbit spermatozoa finally bind a glycoprotein of $M_{\mathrm{r}} 21000$ secreted by the cauda (Garcia et al., 1988) although many in the lower half of the corpus region are already fertile (Bedford, 1966; Orgebin-Crist, 1967). Another glycoprotein secreted by the corpus region, acrosomal stabilizing factor (ASF) (Thomas et al., 1984) will reversibly suppress the fertilizing ability of capacitated rabbit spermatozoa exposed to it, probably by blocking the acrosome reaction (Eng \& Oliphant, 1978). Significantly, spermatozoa retained by ligation in the caput, above the site of ASF production, can develop the ability to fertilize and produce normal young (Bedford, 1988). ASF may therefore not be required for the ability to fertilize.

Since such late sperm surface modifications in the epididymis are not essential for fertilizing ability as such, it is possible that they function as an element of the androgen/low temperatureregulated sperm storage system there. Capacitation, at least that element concerned with the acrosome reaction, could therefore simply constitute a necessary escape from a stable state imposed as a facet of storage in the cauda epididymis, as Thomas et al. (1986) have suggested in their studies of ASF in the rabbit.

In approaching this problem we have taken account of evidence that abdominal temperature not only reduces the capacity for sperm storage, but also appears to modify the pattern of protein synthesis by the caudal epithelium in some respects (Esponda \& Bedford, 1986; Esponda et al., 1990). This paper describes the effect of maintaining the hamster cauda epididymis at abdominal temperature on the capacitation characteristics of the spermatozoa within it.

\section{Materials and Methods}

Animals. Female hamsters, used when 2-4 months of age, were raised and maintained in reverse lighting conditions (lights 17:00-07:00 h). In such conditions, they came into oestrus in the dark period, the peak of ovulation being 13:00-14:00 h.

Male hamsters, 4-6 months old, were raised and maintained in a light-controlled room (lights 05:00-19:00 h). A cryptepididymal state, either unilateral or bilateral (Bedford, 1978; Foldesy \& Bedford, 1982), was established as follows. Animals anaesthetized with i.p. pentobarbital sodium were laparotomized in the mid-line, one testis and epididymis were withdrawn into the abdomen, the gubernaculum was severed and the epididymis was reflected away from the testis. The testis was re-attached to gubernaculum with a suture of 6-0 silk and replaced in the scrotum. The cauda epididymis was retained in the abdomen in a reflected position by means of a loose suture between caudal gubernaculum remnants and the abdominal wall. In some cases, a hemi-cryptepididymal state only was established, with a sham operation (separation of testis and epididymis with incision of gubernaculum, then replacement of testis and epididymis in the scrotum) performed on the control side. A bilateral cryptepididymal state was established in other males used later for mating experiments. All animals were used for experiments between 1 and 3 months after the surgery.

Medium. The medium was a modified Tyrode's solution, m-TALP-3, with the following composition: $101 \cdot 02 \mathrm{mM}$ $\mathrm{NaCl}, 2.68 \mathrm{mM}-\mathrm{KCl}, 1.80 \mathrm{~mm}-\mathrm{CaCl}_{2}, 0.49 \mathrm{~mm}-\mathrm{MgCl}_{2} .6 \mathrm{H}_{2} \mathrm{O}, 0.36 \mathrm{~mm}-\mathrm{NaH}_{2} \mathrm{PO}_{4} \cdot \mathrm{H}{ }_{2} \mathrm{O}, 35 \cdot 70 \mathrm{~mm}-\mathrm{NaHCO}, 4.50 \mathrm{~mm}-$ glucose, $1.0 \mathrm{~mm}$-sodium pyruvate, $9.0 \mathrm{~mm}$-sodium lactate, $0.5 \mathrm{~mm}$-hypotaurine, $0.05 \mathrm{~mm}-(-)$ adrenaline, $50 \mu \mathrm{g}$ gentamicin sulphate $/ \mathrm{ml}$ and $15 \mathrm{mg}$ bovine serum albumin $/ \mathrm{ml}$ (Fraction V; Calbiochem, La Jolla, California). When equilibrated with $5 \% \mathrm{CO}_{2}$ the $\mathrm{pH}$ was $7 \cdot 4$. 
Sperm preparation. After each male was killed with ether, a cryptic or scrotal cauda epididymis was removed, cleaned, and, while applying pressure with fingers, large tubules were punctured with a needle. The dense sperm mass oozing out was collected with small forceps, and placed in the bottom of a tube and over-layered with $3 \mathrm{ml}$ warmed $\left(38^{\circ} \mathrm{C}\right) \mathrm{m}$-TALP-3. After $3-5 \mathrm{~min}$ at room temperature or $38^{\circ} \mathrm{C}$, the upper $0.5-1 \mathrm{ml}$ medium was carefully collected, in which almost $100 \%$ of spermatozoa were actively motile. After adjusting the concentration to $1-1.5 \times 10^{6} / \mathrm{ml}, 0.3 \mathrm{ml}$ of the sperm suspension was placed at the centre of a $35-\mathrm{mm}$ plastic dish, covered with warm mineral oil and incubated at $38^{\circ} \mathrm{C}$ in $5 \% \mathrm{CO}_{2}$. At various times thereafter, the dish was examined microscopically using dark-field or phase-contrast optics, for estimation of percentage motility. A drop was then mounted beneath a coverslip and the percentage of acrosome reactions of $>100$ motile spermatozoa was determined at $\times 450$ magnification. Only motile spermatozoa that had lost the acrosomal carapace were recorded as 'reacted'.

In-vitro fertilization. Oocytes in cumulus oophorus were collected from the oviducal ampulla of superovulated females 16-17 h after hCG injection (Yanagimachi, 1969), freed from cumulus cells in $0 \cdot 1 \%$ bovine testicular hyaluronidase (ICN Pharmaceuticals, Costa Mesa, California) in m-TALP-3, washed and transferred to $0.3 \mathrm{ml}$ m-TALP-3 under mineral oil. Then $5-10 \mu l$ of a sperm suspension freshly prepared from a scrotal or cryptic cauda, as described above, were added without preincubation to give a concentration of $2-5 \times 10^{4} / \mathrm{ml}$. The eggs were removed after $1-4 \mathrm{~h}$ at $38^{\circ} \mathrm{C}$ under $5 \% \mathrm{CO}_{2}$ and examined for evidence of sperm penetration.

Natural mating and fertilization. An oestrous female was placed with a bilaterally cryptepididymal male or with a normal control male at 14:00 h, i.e. during or shortly after ovulation. Mating began immediately and the time of onset of the first intromission was noted. At various times after that, females were killed, their oviducts were removed, and the eggs recovered in m-TALP-3. The eggs were mounted on a slide and were examined for evidence of penetration. An egg was recorded as fertilized when the head of a spermatozoon inside the zona had attached to the oolemma, or a swollen sperm head or male pronucleus with tail was evident within the ooplasm.

To evaluate the ability of the spermatozoon to support normal development, some oestrous hamsters were mated with bilaterally cryptepididymal, or with normal, males, either before ovulation at $07: 00-08: 00 \mathrm{~h}$, or during or shortly after ovulation at 14:00-15:00 h. The females were individually caged and examined for delivery of young 17 days later.

\section{Results}

At 1 month after establishment of a hemi-cryptepididymal state, testicular weights were similar but the abdominally situated cauda epididymis was always smaller and was lighter by $34-70 \%$ than its scrotal counterpart-an effect that reflects smaller tubule capacity and smaller sperm numbers stored (Foldesy \& Bedford, 1982).

When hamster spermatozoa from the scrotal cauda are suspended in TALP medium, within a few minutes the great majority first agglutinate head to head, and then they disperse after $2-3 \mathrm{~h}$, and free spermatozoa display hyperactivated movement (Yanagimachi, 1982). In the present study, these changes occurred sooner in spermatozoa from the cryptic than from the scrotal cauda. At 30 min there were fewer than $5 \%$ free spermatozoa and no hyperactivated spermatozoa in the cryptic or scrotal sperm samples. At $1.5 \mathrm{~h}$, however, $\sim 90 \%$ of the 'cryptic' spermatozoa had dispersed and some $80 \%$ were hyperactivated. By contrast, about $20 \%$ of the 'scrotal' spermatozoa had dispersed and only $10 \%$ were hyperactivated at that time. Subsequently, at $2 \mathrm{~h}$ essentially $100 \%$ of the 'cryptic' spermatozoa had dispersed and were hyperactivated, and about $95 \%$ of the scrotal samples had done so as well.

As can be seen in Fig. 1, the spontaneous acrosome reaction occurred sooner and at a higher rate in spermatozoa released from the cryptic cauda. The implication in both these results, that spermatozoa from the cryptic cauda capacitate sooner in vitro, was borne out by the in-vitro fertilization results. As shown in Fig. 2, when cumulus-free eggs were incubated with epididymal spermatozoa at $0 \mathrm{~h}$, and examined for fertilization at various times thereafter, spermatozoa from the cryptic cauda fertilized sooner under identical conditions than those released from the scrotal cauda.

In a final series of experiments, intact or bilaterally cryptepididymal males were mated naturally with females at or soon after ovulation, when there is only a short delay (about $3 \mathrm{~h}$ ) in sperm transport to the fertilization site (Yanagimachi, 1966; Smith et al., 1987). In this situation in which spermatozoa must penetrate cumulus oophorus as well, spermatozoa ejaculated from the bilaterally cryptepididymal cauda again fertilized eggs in the oviduct sooner than did those of normal 


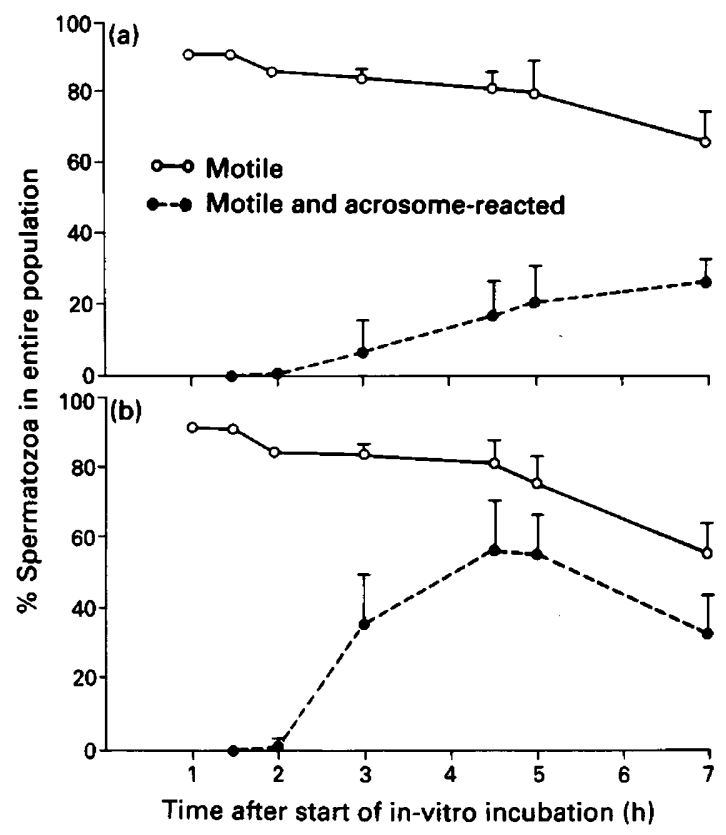

Fig. 1. The motility (survival) and time of onset of the acrosome reaction in spermatozoa collected from (a) the scrotal and (b) the abdominally reflected (cryptic) cauda epididymis of the hamster. Each point represents the mean \pm s.d. of 5 experiments using 5 hemicryptepididymal males.

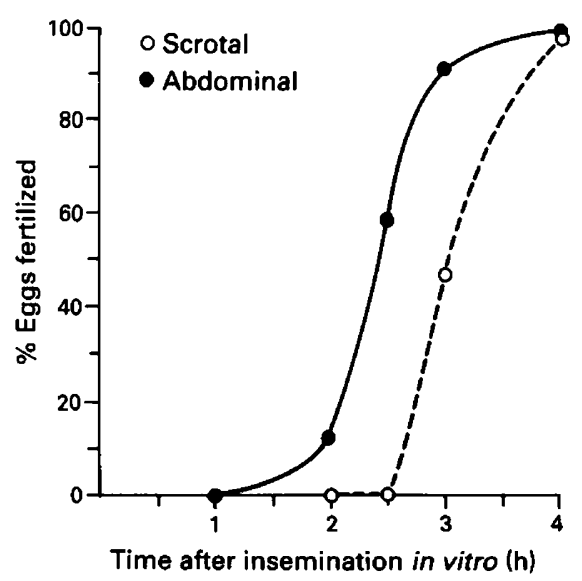

Fig. 2. Progression of the fertilization percentage with time by hamster spermatozoa from the scrotal $(O)$ and abdominally reflected $(O)$ cauda epididymis. Each value based on examination of 30-50 eggs in 3-4 different experiments.

males (Fig. 3). The normality of the spermatozoa and the fertilization process is seen in the fact that 4 of 4 females were mated to cryptepididymal males at or shortly after ovulation, and all gave birth to litters with a mean of 10.75 young per litter. 


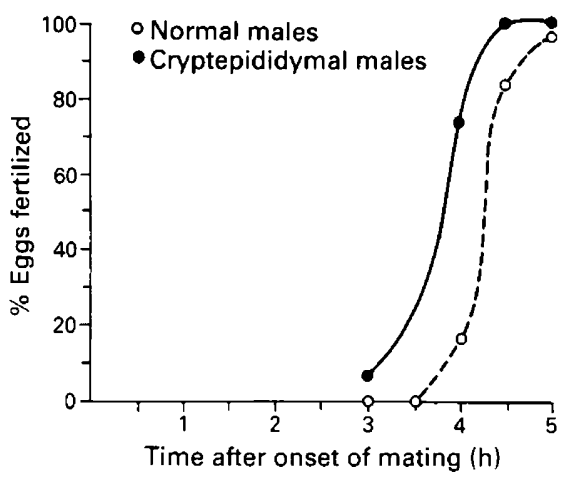

Fig. 3. Progression of the fertilization rate with time in vivo after mating of recently ovulated female hamsters with intact $(O)$ or bilaterally cryptepididymal $(0)$ males. Each value is based on examination of $40-65$ eggs obtained from 4-6 females.

\section{Discussion}

The only direct evidence that the time required for capacitation relates to events undergone in the cauda epididymis is that obtained for the pig, in which numbers of fertile spermatozoa are present even in the upper corpus epididymis (Holtz \& Smidt, 1976). When equal numbers of spermatozoa from the upper corpus were inseminated after ovulation directly into the pig oviduct, a significant proportion of the eggs was penetrated there within $4 \mathrm{~h}$ or less but no potentially fertile cauda spermatozoa had fertilized eggs in the contralateral oviduct (Hunter et al., 1976). However, that temporal advantage of upper corpus spermatozoa was annulled if they were first exposed to caudal secretion (Hunter et al., 1978). A parallel to that last result is the early finding of Weinmann \& Williams (1964), who reported that caudal fluid reversibly inhibits the capacitated state of rabbit spermatozoa.

Such differences in the time of onset of the ability to fertilize seem likely to reflect the action of caudal sperm coating proteins (see 'Introduction'). Therefore, we reasoned that, since body temperature modifies the cauda protein profile in the rat (Esponda \& Bedford, 1986) and the rabbit (Esponda et al., 1990), it might coincidentally change the capacitation characteristics of mature spermatozoa. In accord with this, the present experiments demonstrate that hamster spermatozoa resident in the cauda at abdominal temperature undergo all of the visible consequences of capacitation significantly earlier, by about $30-45 \mathrm{~min}$, than do spermatozoa released from the contralateral scrotal cauda. Moreover, greater absolute numbers of motile spermatozoa underwent a spontaneous acrosome reaction in populations released from the cryptic compared with the scrotal cauda epididymis. Finally, spermatozoa from the cryptic cauda fertilized eggs sooner in vitro and in vivo.

The present results provide some support for the idea that capacitation, in part at least, may represent a necessary escape from a stable state imposed as a function of sperm storage in the cauda epididymis. In light of observations for the rat and rabbit epididymis, it is clearly possible that the effects reported here may reflect a suppression at body temperature of particular macromolecules that normally bind to the sperm surface. The consequences of elevated temperature on the composition of hamster cauda fluid have not yet been examined, but it would be of interest to do so now, since it may prove feasible to relate specific macromolecules to the capacitation process in hamster spermatozoa. Since the patterns of hyperactivation and the acrosome reaction were affected, more than one temperature-sensitive macromolecule may be involved because these two endpoints of capacitation are quite probably regulated by different region-specific sperm surface proteins. 
It seems likely that abdominal temperature will have a variable influence on the composition of cauda fluid (and thus sperm capacitation characteristics) according to species, and it is fortuitous that significant effects on capacitation have been obtainable in the hamster. In the rat, in which the cauda protein profile is changed by body temperature (Esponda \& Bedford, 1986), such effects on sperm function have not been demonstrated. For example, we found that eggs were penetrated as early as $2 \mathrm{~h}$ and $55 \mathrm{~min}$ after bursal insemination of young superovulated rats with spermatozoa from the rat scrotal cauda (a capacitation time significantly shorter than that reported by Austin [1951]) but this was not bettered by spermatozoa released from the abdominal cauda of the rat (J. M. Bedford \& H. Kim, unpublished observations). It may be significant, however, that the HIS protein which coats the rat acrosome in the scrotal cauda (Rifkin \& Olson, 1985) is not temperature-sensitive and is still detectable on rat spermatozoa recovered from the cryptic cauda epididymis 6 weeks after its transposition to the abdomen (J. M. Bedford \& H. Kim, unpublished observations).

In the present experiments, hamster spermatozoa obtained from the abdominal cauda did not fertilize eggs as soon as do fully capacitated spermatozoa in vitro (Yanagimachi, 1982; Smith \& Yanagimachi, 1989) or in vivo (Viriyapanich \& Bedford, 1981). However, some caudal proteins are not modified at abdominal temperature, at least in the rat and rabbit. Therefore, we emphasize that the temperature-sensitive element(s) in the hamster cauda, which may be coating glycoprotein(s), are probably only one amongst several that determine the need and the time for capacitation. Although capacitation may be wholly or partly a legacy of the evolution of regulated sperm storage in the cauda epididymis, this system (and hence the cellular events of capacitation) may depend also on changes undergone before spermatozoa reach the caudal region. For instance, successful binding of HIS protein by the acrosomal region of spermatozoa in the rat cauda requires a prior modification of the sperm head plasmalemma accomplished in the distal caput/upper corpus regions (Rifkin \& Olson, 1985). In the rabbit, similarly, ASF is elaborated by and binds to spermatozoa primarily in the corpus epididymis (Thomas et al., 1984).

The human epididymis is subject to long-term temperature elevation of several degrees centigrade, and certain of its functional features resemble those of the cryptic epididymis in animals (Bedford, 1991b). Some human spermatozoa also are capacitated rapidly in vitro (Overstreet et al., 1980). None the less, although such rapid capacitation is certainly not unprecedented in mammals (e.g. cat; Goodrowe et al., 1989), we speculate whether this ability of some human spermatozoa for rapid capacitation really is innate, or is to some extent a consequence of epididymal function at a chronically elevated temperature.

This work was supported by NIH grant HD-03402 awarded to R.Y.

\section{References}

Austin, C.R. (1951) Observations on the penetration of the sperm into the mammalian egg. Aust. J. Sci. Res. $B$ 4, 581-596.

Bavister, B.D. (1982) Evidence for a role of postovulatory cumulus components in supporting fertilizing ability of hamster spermatozoa. J. Androl. 3, 365-372.

Bedford, J.M. (1966) Development of the fertilizing ability of rabbit spermatozoa in the epididymis. $J$. exp. Zool. 163, 319-330.

Bedford, J.M. (1970) Sperm capacitation and fertilization in mammals. Biol. Reprod., Suppl. 2, 128-158.

Bedford, J.M. (1978) Influence of abdominal temperature on epididymal function in the rat and rabbit. Am. J. Anat. 152, 509-522.
Bedford, J.M. (1983) Significance of the need for sperm capacitation before fertilization in eutherian mammals. Biol. Reprod. 28, 108-120.

Bedford, J.M. (1988) The bearing of epididymal function in strategies for in vitro fertilization. Ann. N.Y. Acad. Sci. 541, 284-291.

Bedford, J.M. (1991a) The co-evolution of mammalian gametes. In $A$ Comparative Overview of Mammalian Fertilization, ch. 1 (in press). Eds B. S. Dunbar \& M. G. O'Rand. Plenum Press, New York.

Bedford, J.M. (1991b) Effects of elevated temperature on the epididymis and testis: experimental studies. In Temperature and Environmental Effects on the Testis, (in press). Ed. A. W. Zorgniotti. Plenum Press, New York. 
Bedford, J.M. \& Hoskins, D.D. (1990) The mammalian spermatozoon: morphology, biochemistry and physiology. In Marshall's Physiology of Reproduction, 4th edn, vol. 2, ch. 5, pp. 379-568. Ed. G. E. Lamming. Churchill Livingston, London.

Bleil, J.D. \& Wassarman, P.M. (1983) Sperm-egg interactions in the mouse: sequence of events and induction of the acrosome reaction by a zona pellucida glycoprotein. Devl Biol. 95, 317-324.

Chang, M.C. (1951) Fertilizing capacity of spermatozoa deposited into the fallopian tubes. Nature, Lond. 168, 1036-1037.

Chen, C. \& Sathananthan, A.H. (1986) Early penetration of human sperm through the vestments of human eggs in vitro. Archs Androl. 16, 183-197.

Cherr, G.N., Lambert, H., Meizel, S. \& Katz, D.F. (1986) In vitro studies of the golden hamster sperm acrosome reaction: completion on the zona pellucida and induction by homologous soluble zonae pellucidae. Devl Biol. 114, 119-131.

Cross, N.L., Morales, P., Overstreet, J.W. \& Hanson, F.W. (1988) Induction of acrosome reactions by the human zona pellucida. Biol. Reprod. 38, 235-244.

Dacheux, J.L. \& Voglmayr, J.K. (1983) Sequence of sperm cell differentiation and its relationship to exogenous fluid proteins in the ram epididymis. Biol. Reprod. 29, 1033-1047.

Dyson, A.L.M.B. \& Orgebin-Crist, M-C. (1973) Effect of hypophysectomy, castration and androgen replacement upon the fertilizing ability of rat epididymal spermatozoa. Endocrinology 93, 391-402.

Eddy, E.M. (1988) The spermatozoon. In The Physiology of Reproduction, vol. I, pp. 27-68. Eds E. Knobil \& J. D. Neill. Raven Press, New York.

Eng, L.A. \& Oliphant, G. (1978) Rabbit sperm reversible decapitation by membrane stabilization with a highly purified glycoprotein from seminal plasma. Biol. Reprod. 19, 1083-1094.

Esponda, P. \& Bedford, J.M. (1986) The influence of body temperature and castration on the protein composition of fluid in the rat cauda epididymidis. J. Reprod. Fert. 78, 505-514.

Esponda, P., Regalado, F. \& Nieto, A. (1990) Effects of temperature and castration on the synthesis of secretory proteins in the rabbit cauda epididymis. In Fertilization in Mammals, p. 416, Abstr. Eds B. D. Bavister, J. M. Cummins \& E. R. S. Roldan. Serono Symposia, U.S.A. Norwell, Massachusetts.

Florman, H.M. \& First, N.L. (1988) The regulation of acrosomal exocytosis. I.Sperm capacitation is required for induction of acrosome reactions by the bovine zona pellucida in vitro. Devl Biol. 138, 453-463.

Foldesy, R.G. \& Bedford, J.M. (1982) Biology of the scrotum. I. Temperature and androgen as determinants of the sperm storage capacity of the rat cauda epididymis. Biol. Reprod. 26, 673-682.

Fournier-Delpech, S., Colas, G., Courot, M., Ortavant, R. \& Brice, G. (1979) Epididymal sperm maturation in the ram: motility, fertilizing ability and embryonic survival after uterine artificial insemination in the ewe. Annls Biol. anim. Biochim. Biophys. 19, 597-605.

Garcia, C., Regalado, F., Lopez de Haro, M.S. \& Nieto, A. (1988). Ultrastructural localization of epididymal secretory proteins associated with the surface of spermatozoa from rabbit cauda epididymis. Histochem. J. 20, 708-714.

Goodrowe, K.L., Howard, J.G., Schmidt, P.M. \& Wildt, D.E. (1989) Reproductive biology of the domestic cat with special reference to endocrinology, sperm function and in-vitro fertilization. J. Reprod. Fert., Suppl. 39, 73-90.

Holtz, W. \& Smidt, D. (1976) The fertilizing capacity of epididymal spermatozoa in the pig. J. Reprod. Fert. 46, 227-229.

Hunter, R.H.F., Holtz, W. \& Henfrey, P.J. (1976) Epididymal function in the boar in relation to the fertilizing ability of spermatozoa. J. Reprod. Fert. 46, 463-466.

Hunter, R.H.F., Holtz, W. \& Hermann, H. (1978) Stabilizing role of epididymal plasma in relation to the capacitation time of boar spermatozoa. Anim. Reprod. Sci. 1, 161-166.

Katz, D.F. \& Yanagimachi, R. (1981) Movement characteristics of hamster and guinea pig spermatozoa upon attachment to the zona pellucida. Biol. Reprod. 25, 785-791.

Orgebin-Crist, M-C. (1967) Sperm maturation in rabbit epididymis. Nature, Lond. 216, 816-818.

Overstreet, J.W., Gould, J.E., Katz, D.F. \& Hanson, F.W. (1980) In vitro capacitation of human spermatozoa after passage through a column of cervical mucus. Fert. Steril. 34, 604-606.

Rifkin, J.M. \& Olson, G.E. (1985) Characterization of maturation-dependent extrinsic proteins of the rat sperm surface. J. Cell Biol. 100, 1582-1591.

Saling, P.M. \& Storey, B.T. (1979) Mouse gamete interaction during fertilization in vitro: chlortetracycline as a fluorescent probe for the mouse sperm acrosome reaction. J. Cell Biol. 83, 544-555.

Smith, T.T. \& Yanagimachi, R. (1989) Capacitation status of hamster spermatozoa in the oviduct at various times after mating. J. Reprod. Fert. 86, 255-261.

Smith, T.T., Koyanagi, F. \& Yanagimachi, R. (1987) Distribution and number of spermatozoa in the oviduct of the golden hamster after natural mating and artificial insemination. Biol. Reprod. 37, 225-234.

Tesarik, J. (1985) Comparison of acrosome reactioninducing activities of human cumulus oophorus, follicular fluid and ionophore A23187 in human sperm populations of proven fertilizing ability in vitro. $J$. Reprod. Fert. 74, 283-388.

Thomas, T.S., Reynolds, A.B. \& Oliphant, G. (1984) Evaluation of the site of synthesis of rabbit sperm acrosome stabilizing factor using immunocytochemical and metabolic labelling techniques. Biol. Reprod. 30, 693-705.

Thomas, T.S., Wilson, L.S., Reynolds, A.B. \& Oliphant, G. (1986) Chemical and physical characteristics of the rabbit sperm acrosome stabilizing factor. Biol. Reprod. 35, 691-703.

Uto, N., Yoshimatsu, N., Lopata, A. \& Yanagimachi, R. (1988) The zona-induced acrosome reaction in hamster spermatozoa. J. exp. Zool. 248, 113-120.

Viriyapanich, P. \& Bedford, J.M. (1981) Sperm capacitation in the fallopian tube of the hamster and its suppression by endocrine factors. J. exp. Zool. 217, 403-407. 
Weinmann, D.E. \& Williams, W.L. (1964) Mechanism of capacitation of rabbit spermatozoa. Nature, Lond. $203,423-423$.

Yanagimachi, R. (1966) Time and process of sperm penetration into hamster ova in vivo and in vitro. $J$. Reprod. Fert. 11, 359-370.

Yanagimachi, R. (1969) In vitro capacitation of hamster spermatozoa by follicular fluid. J. Reprod. Fert. 18, 275-286.

Yanagimachi, R. (1970) The movement of golden hamster spermatozoa before and after capacitation. $J$. Reprod. Fert. 23, 193-196.
Yanagimachi, R. (1981) Mechanisms of fertilization in mammals. In Fertilization and Embryonic Development In Vitro, pp. 81-182. Eds J. D. Biggers \& L. Mastroianni. Academic Press, New York.

Yanagimachi, R. (1982) In Vitro sperm capacitation and fertilization of golden hamster eggs in a chemically defined medium. In In Vitro Fertilization and Embryo Transfer, pp. 65-76. Eds E. S. E. Hafez \& K. Semm. Alan R. Liss, Inc, New York.

Yanagimachi, R. (1988) Mammalian fertilization. In The Physiology of Reproduction, pp. 135-185. Eds E. Knobil \& J. D. Neill. Raven Press, New York.

Received 17 April 1990 